\title{
Uncertainty in flow and sediment projections due to future climate scenarios for the 3S Rivers in the Mekong Basin
}

\author{
Bikesh Shrestha $^{\mathrm{a}}$, Thomas A. Cochrane ${ }^{\mathrm{a}}$, Brian S. Caruso ${ }^{\mathrm{b}}$, Mauricio E. Arias ${ }^{\mathrm{c}}$ and Thanapon \\ $\operatorname{Piman}^{\mathrm{d}}$ \\ aDepartment of Civil and Natural Resources Engineering, University of Canterbury, Private Bag 4800, Christchurch, \\ New Zealand \\ ${ }^{\mathrm{b}}$ USGS Colorado Water Science Center Denver Federal Center, Lakewood, CO 80225, USA \\ ${ }^{c}$ Sustainability Science Program Harvard University, and Department of Civil and Environmental Engineering, \\ University of South Florida, Tampa, FL. \\ ${ }^{\mathrm{d}}$ Mekong River Commission Secretariat, Climate Change and Adaptation Initiative, P.O. Box 6101, Unit 18 Ban \\ Sithane Neua, Sikhottabong District, Vientiane 01000, Lao PDR \\ *Corresponding author. Tel.:+6433642378. E-mail address: tom.cochrane @ canterbury.ac.nz
}

\begin{abstract}
Reliable projections of discharge and sediment are essential for future water and sediment management plans under climate change, but these are subject to numerous uncertainties. This study assessed the uncertainty in flow and sediment projections using the Soil and Water Assessment Tool (SWAT) associated with three Global Climate Models (GCMs), three Representative Concentration Pathways (RCPs) and three model parameter (MP) sets for the 3S Rivers in the Mekong River Basin. The uncertainty was analyzed for the near-term future (20212040 or 2030s) and medium-term future (2051-2070 or 2060s) time horizons. Results show that dominant sources of uncertainty in flow and sediment constituents vary spatially across the $3 \mathrm{~S}$ basin. For peak flow, peak sediment, and wet seasonal flows projection, the greatest uncertainty sources also vary with time horizon. For 95\% low flows and for seasonal and annual flow projections, GCM and MP were the major sources of uncertainty, whereas RCPs had less of an effect. The uncertainty due to RCPs is large for annual sediment load projections. While model parameterization is the major source of uncertainty in the short term (2030s), GCMs and RCPs are the major contributors to uncertainty in flow and sediment projections in the longer term (2060s). Overall, the uncertainty in sediment load projections is larger than the uncertainty in flow projections. In general, our results suggest the need to investigate the major contributing sources of uncertainty in large basins temporally and at different scales, as this can have major consequences for water and sediment management decisions. Further, since model parameterization uncertainty can play a significant role for flow and sediment projections, there
\end{abstract}


is a need to incorporate hydrological model parameter uncertainty in climate change studies and

34 efforts to reduce the parameter uncertainty as much as possible should be considered through a careful calibration and validation process.

Key words: Flow; Sediment; Climate change; Uncertainty; Mekong

\section{Introduction}

Reliable projections of discharge and sediment are essential for successful and efficient water and sediment management plans. Implementation of such plans considering the changing climate requires an understanding of uncertainty in model projections. Estimating the uncertainty and presenting the range of hydrologic projections is thus critical to managing resources under a nonstationary hydrologic regime (Cameron et al., 2000; Maurer, 2007; Milly et al., 2008 as cited by Surfleet and Tullos, 2013). There are various sources of uncertainty related to climate change predictions: (a) the use of Global Climate Models (GCMs) which includes several levels of uncertainty, from lack of knowledge regarding future emissions of greenhouse gases and differing responses of GCMs to greenhouse gases, to uncertainty added by the downscaling used to translate large-scale GCMs to local scales or finer resolution (Maurer, 2007); (b) uncertainty in land use change, which is often overlooked and could play a major role in the overall uncertainty of climate change impacts on hydrology (Bennett et al., 2012); and (c) uncertainty due to hydrological and sediment modeling (Surfleet and Tullos, 2013). Several studies have characterized the uncertainties in flow projection under climate change. For instance, Kay et al. (2009) and Chen et al. (2011) investigated the uncertainties originating from greenhouse gas emission scenarios (GHGES), GCMs, GCM initial conditions, downscaling techniques, hydrological model structures and hydrological model parameters, suggesting that GCM structure is the largest source of uncertainty. For the Mekong River specifically, Thompson et al. (2013) assessed the uncertainty in river flow projections using seven GCMs and three hydrological models, finding that the choice of GCM is the major uncertainty contributor. In California, Maurer (2007) analyzed uncertainty in hydrologic impacts of climate change and concluded that future emissions scenarios play a significant role in the degree of impacts to water resources. Najafi et al. (2011) assessed the uncertainties associated with statistically downscaled outputs from eight GCMs, two emission scenarios, and four hydrologic models. Their results 
62 show that the hydrologic model uncertainty is considerably smaller than GCM uncertainty, 63 except during the dry season, suggesting that the selection of hydrologic model is critical when assessing the hydrologic climate change impact. Others have investigated the uncertainty in downscaling techniques. For instance, Khan et al. (2006) compared three downscaling methods (SDSM, LarsWG and ANN) and showed the significant uncertainties in the downscaled daily precipitation, and daily maximum and minimum temperatures. Although different conclusions were drawn about the contribution of downscaling techniques and hydrologic models to uncertainty, GCMs and emission scenarios are generally considered to be the two major dominant sources of uncertainty in quantifying the climate change impacts on flows (Chen et al., 2011).

The assessment of hydrological model uncertainty is of major importance in hydrologic and sediment modeling (Jiang et al., 2007). It is also essential to advance our understanding of catchment processes (Clark et al., 2011). Traditionally, uncertainties associated with hydrologic models have been considered less important than other sources of uncertainties in climate change impact studies. However, in recent years, the hydrologic community has redirected efforts to better understand the effects of hydrologic modeling approaches to the assessment of climate change impacts (Mendoza et al., 2015). Generally, there are three principal sources of model uncertainty: errors with input and calibration, imperfection in model structures, and uncertainty in model parameters (Refsgaard and Storm, 1996). Model parameters that require calibration uncertainties (Chen et al., 2013; Mendoza et al., 2015). The uncertainty associated with model significant impacts on river flows in different hydrological years (Zhang et al., 2013). One way to study model parameter uncertainty is by calibrating a model using different optimal objective functions (e.g Gädeke et al., 2014; Najafi et al., 2011). Using a different measure of fit (objective function), will likely result in different calibrated parameter values, which is particularly true where there is any sort of interdependence between parameters (Kay et al., 2009). Models perform differently according to each distinct objective function, hence each model calibrated by different objective functions is treated separately (Najafi et al., 2011). 
92 Previous contributions have clearly shown that quantifying the uncertainty at every step in the 93 modelling process (cascading uncertainty) can address the challenge in quantitative assessment of climate change impacts on catchment hydrology considering the full range of uncertainties involved. However, most studies have generally focused on flow. There is still limited 96 knowledge about the uncertainty in sediment projection due to future climate scenarios. The actual response of sediment flux to future climate scenarios in a particular place can vary extensively because it is highly affected by the physical characteristics of the catchment and human activities in it (Berc et al., 2003; Zhang and Nearing, 2005). Further, assessing the uncertainty in flow and sediment projections is of particular importance to regions such as the Mekong in Southeast Asia where there is ongoing rapid development. A number of large, flowregulating dams have been built in recent decades, and over 135 dams are planned in the Mekong River (Cochrane et al., 2014). Development of dams along the main stem of the Mekong River is ongoing, but tributary dam development is proceeding at a faster pace. Of main concern are the Sesan, Srepok, and Sekong (3S) subbasins, where an extensive network of hydropower projects, consisting of individual dams and cascade dams, are planned (Piman et al., 2013). Annual discharge from the $3 \mathrm{~S}$ basin represents approximately $17-20 \%$ of the total annual flows of the Mekong main stream $\left(91,000 \times 10^{6} \mathrm{~m}^{3}\right.$ or an average of $\left.2,886 \mathrm{~m}^{3} / \mathrm{s}\right)$, making it the largest tributary contribution to the Mekong River Basin and therefore of great hydrological importance (Adamson et al., 2009). The $3 \mathrm{~S}$ basin is also a major contributing source of sediment in the Lower Mekong Basin (LMB). Annual sediment load from the $3 \mathrm{~S}$ is estimated at $10-25 \mathrm{Mt}$ (Kondolf et al., 2014), but proposed dams are expected to trap 40 - 80\% (Kummu et al., 2010; Wild and Loucks, 2014). In addition, the $3 \mathrm{~S}$ basin is critical for maintaining flooding regime, aquatic biodiversity and ecosystem services (fish habitats and migration routes) to the downstream Mekong floodplains (Arias et al., 2014; Ziv et al., 2012). Given the hydrological and ecological significance of the $3 \mathrm{~S}$ basin, all dams (constructed, ongoing and future) need to be located, operated and managed in a way that minimizes disruptions to the natural flow regime and sediment fluxes. Changes to water flow and sediment may also alter future power production and reservoir sediment trapping efficiency. Thus, it is imperative that planners and decisionmakers have access to information on uncertainty in flows and sediment loads so these can be accounted for in the design of new dams and the operation of current and future reservoirs. 
122 This study aims to investigate the uncertainty in flow and sediment projections associated with

123 future climate scenarios and model parameterization for the $3 \mathrm{~S}$ basin. Specifically, we evaluate 124 three sources of uncertainty: uncertainty derived from use of (1) three different GCMs, (2) three 125 emission scenarios and (3) three sets of fitted/calibrated model parameters based on three 126 different objective functions. Uncertainty in land use change is not included in this study as it is 127 the scope for further work. Flow and sediment projections for two future time horizons: short 128 term future (2021-2040 or 2030s) and long term future (2051-2070 or 2060s) are compared to 129 the baseline period (1986-2005) using mean annual, seasonal (dry and wet), annual peak and $13095 \%$ low-flow metrics.

\section{2. Methods}

\section{$132 \quad 2.1 \quad$ Study area}

133 The $3 \mathrm{~S}$ basin, a conglomerate of the three transboundary basins of the Sekong, Sesan and Srepok 134 Rivers, is located in the Lower Mekong region in Southeast Asia (Figure 1). The 3S basin covers 135 a total area of $78,645 \mathrm{~km}^{2}$ of which $33 \%$ is in Cambodia, $29 \%$ is in Lao People's Democratic 136 Republic, and $38 \%$ is in Vietnam. The elevation of the basin ranges from 49 to $2360 \mathrm{~m}$ above the 137 mean sea level. The monsoon-driven climate is characterized by a wet season (May to October) 138 and a dry season (November to April). The average annual temperature ranges from 23 to $27^{\circ} \mathrm{C}$. 139 The basin receives about $2600 \mathrm{~mm}$ of average annual rainfall, $88 \%$ of which comes during the 140 wet season. Acrisols (68\%) and Ferralsols (12\%) with sandy clay loam and clay texture are the 141 dominant soils in the basin. Based on the 2003 land use map the basin was dominated by forest 142 (77\%), while agriculture covered nearly $11 \%$ of the total area. Table 1 provides details on basin 143 characteristics, meteorology, and major soil and land use type for all three subbasins. Readers 144 are referred to the Supplementary materials for details on soil distribution and properties, and 145 land use of the study area (Figures S1 and S2 and Table S1). 


\subsection{Hydrological and sediment modeling}

The Soil and Water Assessment Tool, SWAT (Arnold et al., 1998; Srinivasan et al., 1998), was used for simulating flows and sediment in the $3 \mathrm{~S}$ basin because it is one of the most widely used watershed modeling tools, applied extensively for a broad range of water quantity and quality problems worldwide (Gassman et al., 2014). Apart from its proven ability to simulate flows and sediment, SWAT is already used by the Mekong River Commission (MRC) as part of the MRC's modeling Toolbox (MRC, 2010). Between 2010 and 2011, a preliminary SWAT model was calibrated for the 3S basins using actual river flow and rainfall measurements from 1985 to 2006 (MRC, 2011). Details on the SWAT model are provided in the Supplementary Materials.

The main input data for the SWAT model consists of daily precipitation, maximum and minimum air temperatures, wind speed, humidity, solar radiation, and spatial data on DEM, land use and soil layers. All model input data were provided by the Information and Knowledge Management Programme (IKMP) of the MRC. The observed precipitation data provided by MRC are at the subbasin level. MRC uses the MQUAD program (Hardy, 1971) to interpolate and aggregate the observed precipitation data from stations to the subbasins. MQUAD estimates areal rainfall by calculating a multiquadratic surface from available point rain gauge data, such that the surface passes through all gauge points. For details on MQUAD readers are referred to Shaw and Lynn (1972).

\subsubsection{Model calibration, validation and performance evaluation}

The 3S SWAT model was calibrated (1985-2000) and validated (2001-2007) for daily streamflow at seven sites with observed data: Attapeu, Trung Nghai, Kontum, Cau 14, Ban Don, Lumphat and Stung Treng (See locations in Figure 1). The model was only calibrated (20052008) for monthly sediment at three sites: Ban Don, Lumphat and the $3 \mathrm{~S}$ basin outlet. For this study, the sediment load was calibrated, but not validated, because of the scarcity of data in the basin. There is a tradeoff between improving estimates using a longer data set for only calibration, versus using a shorter data set for calibration with additional validation. A study by Muleta and Nicklow (2005) suggests that relatively short calibration and validation periods can adversely affect hydrological model predictions. The model should perform well in the range of conditions for the calibration, but because of the lack of validation estimates may possibly not be 
176 as good outside that range or time period, or for more extreme conditions. Hence, instead of 177 splitting the short period of observed sediment data into calibration and validation periods, the 178 whole set of observed data was used for calibration to improve model performance. There are 179 several studies (for example Hanratty and Stefan, 1998; Shrestha et al., 2013) where calibration 180 only was performed for improving sediment load estimates when short periods of observed data were available. Total suspended solids (TSS) measurements were available for the Lumphat and 182 Bandon stations in the $3 \mathrm{~S}$ basin, and for Pakse, Stung Treng and Kratie in the Mekong River 183 (near the vicinity of the 3S basin outlet). Monthly sediment estimates were used to calibrate the 184 185 186 model at Ban Don, Lumphat and 3S outlet. As no direct sediment measurements were made at the $3 \mathrm{~S}$ outlet for the calibration/validation period, sediment loads at the $3 \mathrm{~S}$ basin outlets $\left(S E D_{3 S}\right)$ were approximated as follows:

$$
S E D_{3 s}=\text { TSS }_{\text {Stung Treng }} *\left(Q_{\text {Stung Treng }}-Q_{\text {pakse }}\right)
$$

where $T S S_{\text {Stung Treng }}$ is the TSS concentrations in the Mekong River at Stung Treng, and $Q_{\text {Stung Treng }}$ and $Q_{\text {Pakse }}$ are the river flows along the Mekong at Stung Treng and Pakse, respectively.

Equation 2.1 was used to overcome two major difficulties: (a) lack of long-term TSS monitoring at the $3 \mathrm{~S}$ outlet, and (b) monthly TSS concentrations and computed sediment loads at the farthest upstream station in the study area (Pakse) are often larger than at the downstream stations Stung Treng and Kratie. This counter intuitive decrease in sediment loads downstream in the Lower Mekong has been risen as an issue before (Koehnken, 2012), and others have explained this phenomenon as a result of the overall deposition-dominated nature of the river channels in the lower Mekong (Lu et al., 2014). Mean monthly sediment loads for the three stations were estimated using the program LOADEST (Runkel et al., 2004). LOADEST estimates mean monthly sediment loads using rating curves developed from the best-fitted polynomial model and coefficients based on an Adjusted Maximum Likelihood Estimation Method. Due to unavailability of SSC data, TSS data were used for this study. TSS stands for Total Suspended Solids, an indicator primarily used for water pollution characterization and it is derived from filtering a small water subsample $(100-250 \mathrm{~mL})$ from a single grab sample collected at arm reach below the water surface in the middle of the river channel. SSC stands for Suspended Sediment Concentration, an indicator specifically scoped for natural waters, in which the full content of 
relatively large samples (1-L normally) are obtained in order to represent the entire depth of the water body. The difference between TSS and SSC decrease when the fraction of small particles is large (Gray et al., 2000). The suspended sediments in the Lower Mekong River are mainly composed of silt- and clay-sized particles (Walling, 2005). Koehnken (2012) indicated that the suspended sediments are mostly comprised of silt and clay downstream of Pakse and typically all of the suspended sediments are less than $63 \mu \mathrm{m}$ in the Mekong at Kratie. In general suspended particles that are finer than $60 \mu \mathrm{m}$ are uniformly vertically concentrated in rivers (Guy and Norman, 1970; Partheniades, 1977). Thus, the difference between loads estimated with TSS and SC measurements in this part of the lower Mekong should not be expected to be as large as what others have found in the basin's upper reaches upstream of Pakse (Walling, 2008).

For the SWAT model, parameters are spatially designated at watershed, subbasin and Hydrological Response Unit (HRU: the lumped land area within the subbasin that comprise unique land cover, soil, slope and management combinations) levels; hence a two-stage calibration procedure was adopted in this study. First, the model was calibrated from upstream to downstream for parameters specified at subbasin and HRU levels. Second, once the parameters for subbasin and HRU levels were calibrated, they were kept unchanged and parameters specified at the watershed level were calibrated.

The SWAT-CUP software (Abbaspour, 2008) was used for the automatic calibration of the 3S SWAT model. The user interaction or manual component of the SWAT-CUP calibration forces the user to obtain a better understanding of the overall hydrologic processes (e.g., baseflow ratios, evapotranspiration, sediment sources and sinks, crop yields, and nutrient balances) and of parameter sensitivity (Arnold et al., 2012). The Sequential Uncertainty Fitting (SUFI-2) algorithm (Abbaspour et al., 2004; Abbaspour et al., 2007) was used for the parameter optimization. SUFI-2 enables sensitivity analysis, calibration, validation, and uncertainty analysis of SWAT models. This algorithm is known to produce comparable results with widely used other auto-calibration methods (Yang et al., 2008). In order to run the automatic calibration in SUFI-2, the parameters to be calibrated (most sensitive ones) and their initial ranges (Table 2) were specified based on a literature review (Neitsch et al., 2011; Shrestha et al., 2013). In SUFI2 there are two ways to change parameter values during calibration: directly changing the absolute value of a parameter, and changing the absolute value relative to the initial value 
236

237

238

239

240

241

242

243

244

245

246

247

248

249

250

251

252

253

254

255

256

257

258

259

260

261

262

specified for the parameter. Readers are referred to Abbaspour et al. (2007) for details of SUFI-2 approach.

The calibrated models were evaluated by comparing the simulated with the observed constituents using the Nash-Sutcliffe efficiency (NS), Coefficient of Determination $\left(\mathrm{R}^{2}\right)$ and percent bias (PBIAS). NS and $\mathrm{R}^{2}$ are the most widely applied and well recommended performance measures (Masih et al., 2011), and PBIAS is also recommended as one of the measures that should be included in model performance reports (Moriasi et al., 2007).

\subsubsection{Model uncertainty: uncertainty in parameter estimation}

The final model parameter ranges are always conditioned on the form of the objective function (Abbaspour et al., 2004). The objective function used in the generation of the response surface (objective criteria) is crucial in the automatic calibration process (Gan et al., 1997). To address the uncertainty in parameter estimation, three different objective functions were used to calibrate the $3 \mathrm{~S}$ SWAT model. The three different objective functions were selected based on recommendations in the literature and options available in SWAT-CUP. During the automatic calibration process in the SWAT-CUP software using the SUFI-2 optimizing algorithm, the objective function and meaningful absolute minimum and maximum ranges for the parameters being optimized were defined initially. Parameters were then calibrated using a Latin Hypercube sampling procedure three times for each objective function; the first was derived from 1000 simulations and the subsequent two were derived from 500 simulations. Out of the best three resulting parameter sets, the parameter set that performed well for all performance indicators considered (NS, $\mathrm{R}^{2}$ and PBIAS) was chosen. As a result, three different model configurations were used in this study in order to assess the uncertainty in parameter estimation (Figure 2).

\section{Nash-Sutcliffe efficiency (NS)}

NS is a normalized statistic that determines the relative magnitude of the residual variance compared to the measured data variance (Nash and Sutcliffe, 1970). It indicates how well the plot of observed versus simulated data fits the 1:1 line. NS is computed as:

$$
N S=1-\frac{\sum_{i}\left(Q_{m}-Q_{s}\right)_{i}^{2}}{\sum_{i}\left(Q_{m, i}-\bar{Q}_{m}\right)^{2}}
$$


263 where $Q_{m, i}$ is the observed value (sediment load or flow) at time-step $i, Q_{s}$ is the simulated value

264 at time-step $i, \bar{Q}_{m}$ is the mean observed value.

265 NS is widely used (Gupta et al., 2009; Moriasi et al., 2007) and is the best objective function for 266 reflecting the overall fit of a hydrograph (Servat and Dezetter, 1991). NS ranges between 267 negative infinity to 1 , where 1 shows a perfect model. Values between 0 and 1 are generally 268 viewed as acceptable levels of performance.

269 Ratio of Standard Deviation of Observations to Root Mean Square Error (RSR)

270 RSR standardizes the Root Mean Square Error using the observations' standard deviation. RSR 271 incorporates the benefits of error index statistics and includes a scaling/normalization factor, so 272 that the resulting statistics and reported values can apply to various constituents (Moriasi et al., 273 2007). RSR is calculated as:

274

$$
R S R=\frac{\sqrt{\sum_{i=1}^{n}\left(Q_{m}-Q_{s}\right)_{i}^{2}}}{\sqrt{\sum_{i=1}^{n}\left(Q_{m}-\bar{Q}_{m}\right)^{2}}}
$$

275 where $Q_{m, i}$ is the observed value at time-step $i, Q_{s}$ is the simulated value at time-step $i, \bar{Q}_{m}$ is the 276 mean observed value, $n$ is the total number of time-steps.

277 RSR varies from 0 to larger positive values. The lower the RSR, the better the model fit.

$278 \quad$ Mean square error (MSE)

279 MSE measures the average of the squares of the errors. The equation for MSE is:

280

$$
M S E=\frac{1}{n} \sum_{i=1}^{n}\left(Q_{m}-Q_{S}\right)_{i}^{2}
$$

281 where $Q_{m, i}$ is the observed value at time-step $i, Q_{s}$ is the simulated value at time-step $i, n$ is the 282 total number of time-steps.

283 MSE is the most commonly used criteria for calibration and evaluation of hydrological models 284 with observed data (Gupta et al., 2009). MSE varies from 0 to infinity. An MSE value of 0 285 indicates a perfect fit. 
In general, these objective functions tend to better fit the higher portions of the hydrograph at the expense of the lower portions to achieve a higher value of the objective function (Krause et al., 2005).

\subsection{Future climate scenarios and downscaling technique}

\subsubsection{GCMs and emission scenarios}

A previous study on selection of climate change scenarios for the Lower Mekong (MRC, 2015) found that in order to maximize the amount of uncertainty captured, climate change scenarios should be developed based on three GCMs (GISS-E2-R-CC, IPSL-CM5-MR and GFDL-CM3) and three emission scenario (referred to as Representative Concentration Pathways (RCPs)): RCP2.6 (low emissions), RCP6.0 (medium) and RCP8.5 (high). Further, these three GCMs are selected based on their satisfactory performance in simulating the most influencing climate processes in the Asian monsoon region (MRC, 2015). Hence, for this study the aforementioned three GCMs and three RCPs are used (Table 3). Details of three RCPs used are provided in the Supplementary Materials (Table S2).

The GCMs selected are part of the Coupled Model Intercomparison Project-5 (CMIP5) models, i.e. IPCC $5^{\text {th }}$ Assessment Report GCMs. The CMIP5 models are newer, of higher resolution and more sophisticated than the older CMIP3, i.e. IPCC $4^{\text {th }}$ Assessment Report GCMs (MRC, 2015). For rainfall of the East Asian monsoon, the CMIP5 models outperformed the CMIP3 models in terms of the interannual variability and intraseasonal variability (Sperber et al., 2013). The CMIP5 models are also superior to the older CMIP3 models in terms of utilizing the most up to date scientific information and computing technology (MRC, 2015).

The two time horizons, short term future (2021-2040) and long term future (2051-2070), were used to produce climate change projections for the $3 \mathrm{~S}$ basin. These time horizons are critical for planning purposes and have been used in previous MRC work.

\subsubsection{Climate model downscaling}

The climate change projections dataset used for this study was provided by the MRC Climate Change and Adaptation Initiative (CCAI). This dataset includes SWAT model-ready monthly 'change factors' for precipitation, temperature, solar radiation and relative humidity. MRC CCAI uses SimCLIM software to downscale the climate projections. SimCLIM is an integrated 
assessment model that was originally developed to enable integrated assessments of the effects of climate change on New Zealand's environment (Kenny et al., 1995). It is designed by CLIM systems, which uses projections of global mean temperature change and combines them with spatial patterns of change from GCM simulations to derive future climate projections for a range of variables at high spatial resolutions. SimCLIM employs pattern scaling plus bilinear interpolation to downscale the GCM outputs. Pattern scaling constructs future climate time series by linearly relating change in any variable (at any region or time in the future) with the change in global mean temperature for the corresponding GHG emission and time period. In pattern scaling for a given climate variable $(V)$, its anomaly $\Delta V^{*}$ for a particular grid cell $i$, month $j$ and year or period $y$ under an emission scenario is given by:

$$
\Delta V_{y i j}^{*}=\Delta T_{y} \Delta V_{i j}^{\prime}
$$

where $\Delta T$ is the change in annual global mean temperature and $\Delta V_{i j}^{\prime}$ is the local change pattern value.

$\Delta V_{i j}^{\prime}$ is calculated from the GCM simulation anomaly $\left(\Delta V_{y i j}\right)$ using linear least squares regression as:

$$
\Delta V_{i j}^{\prime}=\frac{\sum_{y=1}^{m} \Delta T_{y} \Delta V_{y i j}}{\sum_{y=1}^{m}\left(\Delta T_{y}\right)^{2}}
$$

where $m$ is the number of future 5-year sample periods used (i.e from 2006-2100, 19 periods in total).

Pattern scaling is done at the GCM grid scale, hence it does not downscale. Downscaled information is obtained by bilinear interpolation. This method interpolates the pattern scaled data from the original resolution (i.e the resolution of the GCM) to $0.5^{\circ} \times 0.5^{\circ}$ grids which ensures consistency and allows comparison across the different GCMs, different time horizons, different emission scenarios, different variables, and with the baseline data.

SimCLIM provides 'change factors' and 'absolute projected values' to quantify the projected alterations to the climate. Change factors are the differences between GCM future and GCM historical climate simulations while absolute projected values are the actual GCM future climate change simulations. MRC CCAI uses change factors to quantify the projected alterations to the 
342 climate because the change factor approach represents the simplest and most practical way to

343 produce scenarios based on multiple GCMs, emission scenarios, sensitivities, time horizons and 344 locations (MRC, 2015).

345

346

347

348

349

350

351

352

353

354

355

356

357

358

359

360

361

362

363

364

365

366

367

368

369

\subsection{Uncertainty analysis}

The uncertainty analysis for this study is based on the methodology suggested by Chen et al. (2011). We used three different 3S SWAT model configurations (use of separate parameter solutions sets) for each of three GCMs and three RCPs combinations for a total of 27 simulations for each of two time horizons (Table 4). The flow and sediment projections from the same source of uncertainty were first grouped and then averaged for a mean projection and compared with the baseline period (1986-2005). For instance, to investigate the uncertainty linked to GCMs, flow and sediment projections were grouped by GCMs (three GCMs), each group including flow and sediment projections from three emission scenarios and three model configurations.

The mean flow and sediment loads for the baseline period were represented by the average of the simulations of the three model configurations for the baseline period. The ranges of difference between the future hydrologic projections resulting from the use of different GCM, RCP and MP as compared to the baseline are referred to as uncertainty due to GCM, RCP and MP, respectively. Five major hydrological parameters for flow (annual, dry, wet, peak and 95\% low flows) and two parameters for sediment (total annual and peak sediments) were calculated to investigate each source of uncertainty.

\section{Results and discussion}

\subsection{Calibration and Validation of the SWAT model}

The comparisons for the observed and model simulated discharge and sediment load show an overall good agreement in seasonal patterns with some discrepancies in peak events and interannual variability (Figure 3 and Figure 4). None of the model configurations (SWAT NS, SWAT $_{\text {RSR, }}$ SWATMSE) were able to capture peak flows for three stations (Kontum, Cau 14 and Ban Don; Figure 3), which might be attributed to precipitation data, potential errors in the observed stream flow data (especially during high flows), and inadequate representation of 
natural or man-made processes in the model. Similarly, none of the model configurations were able to capture the peak sediment events (Figure 4). This mismatch in peak sediment may be due to uncertainty in the modified universal soil loss equation (MUSLE) used in SWAT. MUSLE tends to overpredict the sediment yields for small events and underpredict yields for large events (Jackson et al., 1986; Johnson et al., 1986). Further, high sediment yields during the wet season may be caused by effects that cannot be captured by the model; for instance, heavy (local) rainfall-induced landslides, river bank collapses or human activities. Moreover, the model's poor capture of the interannual variability in sediment loads could be related to the uncertainty in sediment sampling itself, which for the dataset used to calibrate this model was done based on grab samples of suspended solids as opposed to detailed suspended sediment concentration data (Walling, 2008), which only began to be monitored very recently in the $3 \mathrm{~S}$ and for which only one year of data are available at the 3S outlet (Koehnken, 2014).

The performance of the $3 \mathrm{~S}$ SWAT model for the three model configurations was also verified in terms of three different statistical parameters/indicators (Table 5 and Table 6). In general, the results indicate that all three model configurations performed satisfactorily with performance indicators within the expected range for SWAT applications in other data-scarce basins (Ndomba et al., 2008a; Ndomba et al., 2008b; Rostamian et al., 2008; Setegn et al., 2010; Shrestha et al., 2013). To our knowledge, there is only one other SWAT application that has been calibrated for suspended sediments in the Mekong (Shrestha et al., 2013), and a comparison of calibration results (all $\mathrm{R}^{2}$ and NS values below 0.60 ) highlights the difficulty of accurately calibrating a sediment model in this basin. Assessment of the sediment flux of a river system is predominantly dependent upon the number and locations of measuring stations, the amount of available data, reliability, accuracy, the temporal resolution of the data, and, finally, the length of the records (Walling, 2008). A number of key SWAT parameters (for example, SPCON, SPEXP and PRF) can only have single values across the whole watershed; however, in a large watershed these parameters may vary considerably and this restriction could affect modeling performance (Gong et al., 2012). The PBIAS for flow tends to be higher in the validation period as compared to the calibration period, which might be due to over fitting of volume-sensitive parameters (Bennett et al., 2012), assumptions that the calibrated parameters are stationary (and valid for both calibration and validation periods), or not incorporating dynamic land cover. 
Based on the visual and statistical performance indicators comparison, the overall performance of the models was not affected substantially when different objective functions were used for calibration. The resulting range of selected parameters used for the model calibration is provided in the Supplementary Material (Figure S3).

\subsection{Climate change projections}

Projected changes in the seasonal (dry and wet) and annual temperature (differences) and precipitation (ratio) for the $3 \mathrm{~S}$ basin are presented by GCMs and emission scenarios (RCP) to illustrate each source of uncertainty (Figure 5). Climate projections from the same source are first grouped and then averaged for a mean climate projection. Further, the changes were also calculated for the three subbasins (Sekong, Sesan and Srepok) to reflect the variability of projections across the $3 \mathrm{~S}$ basin. Readers are referred to the Supplementary Material (Figure S4) for results at the subbasin level.

All GCMs and RCPs show an increase in seasonal and annual temperature across the 3S basin, with similar variability in shifts for all subbasins, for future horizons. In the case of precipitation for all subbasins, two GCMs (except GFDL-CM3) and RCPs suggest decreases in the mean dry season precipitation. In general, all projections show an increase in the wet season and annual precipitation over the $3 \mathrm{~S}$ basin. However, for the Srepok subbasin, GISS-E2-R-CC GCM suggests a decrease in wet season and annual precipitation.

In contrast to temperature, the variability in annual and seasonal precipitation differs among subbasins. For instance, the projected changes in wet season precipitation for 2060s (2051 2070) range from 1.0 to $8.5 \%$ for Sekong, 0.9 to $7.4 \%$ for Sesan, and -5.4 to $5.0 \%$ for the Srepok subbasin. Projected changes in precipitation are not unidirectional and vary depending on the GCMs, time period, and season. The bidirectional changes in precipitation may be due to the complexity in interpreting precipitation, as different GCMs often do not agree with regard to changes in both magnitude and direction at a specific location (Girvetz et al., 2009).

The uncertainties related to GCMs and RCPs for two variables increase with time as shown by the higher variability in temperature and precipitation changes from the 2030's and 2060's projections (Figure 5). The uncertainty linked to the GCMs is higher than for RCPs for seasonal and annual precipitation for the $3 \mathrm{~S}$ basin. In contrast, basin wide analysis showed that the 
uncertainty related to the GCMs is smaller than for RCPs for wet season and annual precipitation for the Sekong and Sesan subbasins. The uncertainty related to GCMs arises due to incomplete understanding of the physical processes and the limitations in implementing such understanding in the models (Vetter et al., 2015). For precipitation projections, uncertainty due to GCMs is generally the dominant source of uncertainty for longer time horizons (Hawkins and Sutton, 2011). Uncertainty related to RCPs is larger for temperature than precipitation, and this is even greater for the 2060s period than for the 2030s period, which largely agrees with other studies (Yip et al., 2011).

\subsection{Uncertainty analysis}

\subsubsection{Flow}

The cumulative distribution functions (CDFs) of peak flow and 95\% low flow changes for the two future time periods (or horizons) (2030s and 2060s) were analyzed for the $3 \mathrm{~S}$ basin (Figures 6 and 7, respectively). CDFs are plotted to compare the importance of all three uncertainty components. The peak flow is likely to increase for both time horizons. For example, for the 2060s (2051-2070) period using GISS, GFDL and IPSL GCMs, there is a likelihood of nearly $64 \%, 74 \%$ and 69\%, respectively, of increased (i.e., positive changes) peak flow (Figure 6). Model parameter is the main contributor to uncertainty in peak flow for the 2030s period, while $\mathrm{RCP}$ is the main source of uncertainty for the 2060s period which is clearly indicated by the large differences between CDFs of RCP for more extreme peak flow increases. For the 2060s, the likelihood of increased peak flow ranges from 54.1\% under RCP 2.6 to $78.9 \%$ under RCP 8.5. GCM is the source of uncertainty with the least influence for both time periods. In contrast, the low flow is likely to decrease for all future horizons except for GFDL GCM, which predicts about $68 \%$ and $75 \%$ likelihood of increased low flows for the 2030s and 2060s periods, respectively (Figure 7). In comparison, the uncertainty due to GCM is large, which is mainly due to the GFDL model. RCPs provide the smallest source of uncertainty for low flow for the 2030s, while model parameter is the least source of uncertainty for the 2060 s period.

Results at the subbasin level suggest that there is substantial spatial variability in changes in peak and low flows across the $3 \mathrm{~S}$ basin (Figure 8). For the Sekong subbasin, RCP is the main contributor to uncertainty of peak flow for both periods. For instance, the absolute differences (i.e., absolute differences between minimum and maximum values as shown in Figure 8) in the 
peak flow for GCM, RCP and model parameter are $2.9 \%, 4.1 \%$ and $1.2 \%$, respectively. In comparison, the largest absolute difference is for RCP which makes RCP the largest source of uncertainty. Model parameters result in the least uncertainty among sources. For low flows, the uncertainty due to GCM is large and mainly due to the GFDL model. Model parameter is the least source of uncertainty for both periods. With regard to the Sesan subbasin, model parameter is the main source of uncertainty for both periods, while GCM is the least contributor to uncertainty of peak flow. Model parameter is the main source of uncertainty and RCP is the least source of uncertainty for low flow projections for both time horizons. For the Srepok subbasin, model parameter is the main contributor to uncertainty of peak flow for the 2030s period, while GCM is the main source of uncertainty for the 2060s period. RCP result in the least uncertainty among sources. For low flows, model parameter is the main contributor and RCP is the least contributor to uncertainty for all time horizons.

In general, the greatest source of uncertainty for peak flows projection varies both with time horizon and space, while for low flows the major contributing sources of uncertainty vary spatially primarily. Nevertheless, model parameter and GCM are the two major contributors to uncertainty in low-flow projections, while RCPs have a lesser effect. The uncertainties in peak and low flow projection due to hydrological model parameters can be significant, which was also concluded by Wilby and Harris (2006). Najafi et al. (2011) also found that the hydrologic model uncertainties become important when analyzing dry season flows. Hydrological model parameter uncertainty and careful calibration and validation to reduce parameter uncertainty should be taken into account in practical use of hydrological models for decision making (Zhang et al., 2014). The parameter uncertainty should be properly addressed in climate change studies to avoid an over-confident portrayal of climate change impacts (Mendoza et al., 2015).

The changes in seasonal as well as annual flows are bidirectional (Figure 9 and Table 7) as the projections of hydrological changes in the basin are highly dependent on the direction of the projected changes in precipitation (Kingston et al., 2011; Shrestha et al., 2013). Similar to peak and low flows, the dominant source of uncertainty for seasonal and annual flow varies spatially across the $3 \mathrm{~S}$ basin (Table 7). For the Sekong subbasin, GCM is the major contributing source of uncertainty for seasonal and annual flow for all future time horizons. In contrast, uncertainty due to model parameter is larger for seasonal and annual flow in the Sesan. For the Srepok subbasin, 
uncertainty due to model parameter dominates during the 2030s period for seasonal flows and for dry season flow during the 2060s, which is mainly caused by model parameterization in the RSR model configuration. Spatial variability may be due to sensitivity of basin runoff processes to variability in climate, physiographic factors and spread/range of hydrological model parameters used to capture the runoff process in the basin. For instance, RCPs represent an important driving factor for basins where the more certain projected trends in temperature are probably more relevant for projected discharges than the precipitation process (Vetter et al., 2015). Variability in spread/range of the selected hydrological model parameter(s) can have variable influences in the watersheds and the uncertainty because hydrologic parameter uncertainty tends to be larger when GCM and emissions anomalies are larger (Bennett et al., 2012). Parameter sets with similar performance, but located in different regions of the parameter space, can generate a range of projections for future catchment behavior (Mendoza et al., 2015). Our results support that optimal solutions may lead to a wide range, and spatially variable set of hydrological model parameters (Figure S3 in the Supplementary Material).

In general, we found that in the short term (2030s) uncertainty due to model parameter can be most significant for wet season flows, but in the longer term (2060s) GCM is the major contributing source of uncertainty for seasonal as well as annual flow projections (Figure 9). The dominance of uncertainty due to GCM has been reported before (e.g., Chen et al., 2011), mostly due to the large uncertainty contribution of climate models for precipitation projections (Vetter et al., 2015). The change in the major source of uncertainty with time, however, is a key finding from this research that should be studied in more detail as it could result in important implications for the way climate change scenarios are translated from GCMs to watershed models.

\subsubsection{Sediment}

The cumulative distribution functions (CDFs) of peak sediment load changes were plotted to compare three uncertainty components in peak sediment load projection for the 2030s and 2060s time horizons (Figure 10). In general, all simulations show that the peak sediment load is likely to increase in the future. For instance, under emission scenarios the likelihoods of increased peak sediment load ranges between 63.5 and $94 \%$ for the $3 \mathrm{~S}$ basin as a whole, with subbasin variability of $61.19-93.10 \%, 63.38-78.91 \%$ and $56.67-72.50 \%$ for the Sekong, Sesan and 
519 Srepok subbasins, respectively. Overall, our results for the $3 \mathrm{~S}$ basin suggest that model 520 parameter is the main contributor to uncertainty of peak sediment load in the short term (2030s), while RCP is the main source of uncertainty in the longer term (2060s). The choice of GCM

522 results in the smallest source of uncertainty.

523 Similar to peak flows, the dominant source of uncertainty for peak sediment projection is subbasin dependent (Figure 11). The ranking of sources of uncertainty for Sekong and Sesan subbasins load are the same as for the entire 3S basin. In contrast, in the Srepok uncertainty due to GCM dominates the uncertainty in peak sediment load projections. This is mainly due to GISS GCM that predicts decrease in peak sediment load for the Srepok in opposite to other two subbasins. Model parameter is the smallest source of uncertainty for peak sediment load for the 2060s period and the uncertainty due to RCPs is small for 2030s.

Basin wide analysis shows that the annual sediment load is likely to increase in the future (Figure 12), despite differences in the direction of change among subbasins load (Table 8). One of the possible explanations for this spatial variability could be due to differences in hydrologic properties (like precipitation, temperature). For instance, the changes in wet season precipitation for the Srepok appeared to be bidirectional which is opposite from the other two subbasins (where changes are unidirectional). The wet season precipitation change for the Srepok ranges from -3.0 to $2.8 \%$ for the 2030 s and -5.4 to $5.0 \%$ for 2060 s. This larger response to precipitation events may explain why there is bidirectional change in annual sediment yield. Dry season sediment loads are an insignificant fraction compared to wet season sediment loads for the $3 \mathrm{~S}$ basin. In general, changes in sediment loads follow patterns of flow, however our results indicate bidirectional flow projections can all lead to increasing sediment load for both periods. The changes of sediment yield and discharge in response to climate change do not always happen in the same direction (Shrestha et al., 2013). This also suggests that the sediment yield projection is more sensitive to temperature and rainfall changes than flow. Decrease in rainfall and increase in temperature can lead to water stress, which reduces the growth of plants and hence increases the erosion rate. This change in erosion rate causes change in the sediment flux in a river, which was also outlined by (Zhu et al., 2008). The temporal and spatial variability in the major contributing sources of uncertainty for the annual sediment load projections is also observed across the $3 \mathrm{~S}$ basin (Table 8). Results of the subbasin wide analysis show that model parameter and RCP are 
the largest sources of uncertainty for the annual sediment load during the 2030s and uncertainty due to RCPs and GCMs dominates for the 2060s.

In general, the uncertainty due to RCPs is larger than other two sources of uncertainty for the annual sediment load projection of the $3 \mathrm{~S}$ basin (Figure 12). The uncertainty due to RCP is large mainly due to RCP 8.5, in which change signals are expected to be larger (i.e emissions continue to rise heading to radiative forcing $>8.5 \mathrm{~W} / \mathrm{m}^{2}$ in 2100). This indicates that annual sediment projections for the $3 \mathrm{~S}$ basin have a much larger response to temperature changes than precipitation changes. Other studies have shown that sediment yield can be influenced by temperature changes. Harrison (2000) found temperature was exponentially related to the erosion rates, and Syvitski et al. (2003) indicated there was a negative relationship between temperature and sediment load in a tropical zone. Increased temperature may increase the soil erosion rate and, consequently, increase sediment flux through its influence on vegetation and weathering ( $\mathrm{Li}$ et al., 2011; Zhu et al., 2008). SWAT simulates plant growth based on daily accumulated heat units where temperature is a major factor governing the plant growth. Increase in temperature may result in water stress, which reduces plant growth and hence increases the erosion rate. The decrease in sediment flux may be due to significant influence of increased evapotranspiration and crop growth process under warmer climate (Bogaart et al., 2003). Further, it is also interesting to note that the uncertainty in the sediment load projection is larger than the uncertainty in the flow projections, which is most probably due to higher changes in sediment yields than the corresponding changes in flow. For instance, the annual sediment load change for the $3 \mathrm{~S}$ basin ranges from 4.8 to $50.1 \%$ for 2060 s while for the flow the changes ranges from -0.6 to $3.1 \%$. A study by Shrestha et al. (2013) has also concluded that the impact of climate change on sediment yield can be greater than on flow. Although analysis of uncertainty due to land use change is not included in this study, it is important to note that the sediment prediction uncertainty due to the climate signal might be smaller than land use change uncertainty. A comparison of the contributions of climate and land use change in China by Ma et al. (2014) and Dai et al. (2009) for instance, showed that projected land use change governed changes in sediment yield. Hence, it is essential to include uncertainty in land use change as it could help understand the range and major sources of uncertainties for better sediment management planning. 


\section{Conclusion}

This study investigated the uncertainty in flow and sediment projections from climate change for the 3S basin using SWAT. Three sources of uncertainty were evaluated: GCMs, RCPs, and model parameterization. The analysis of climate change projections results showed that all of the GCMs and RCPs suggest an increase in seasonal and annual temperature across the $3 \mathrm{~S}$ basin, with similar variability in shifts for the Sekong, Sesan and Srepok subbasins for the 2030s and 2060s. In contrast to temperature, projected changes in precipitation are bidirectional and vary depending on the GCM, time horizon, season, and subbasin. GCM is the major contributor to uncertainty in dry season precipitation projections, whereas uncertainty related to RCP is large for wet/annual precipitation and temperature across the $3 \mathrm{~S}$ basin.

A major finding of this study is that the dominant sources of uncertainty in flow and sediment constituents vary temporally, and that results are scale dependent (basin or subbasin scale). Model parameters and GCMs are the two major contributors to the uncertainty in low flow projections, whereas RCPs had less of an effect. Model parameterization is the major contributing source of uncertainty for wet seasonal flow projections in the short term (2030s), whereas uncertainty due to GCMs dominates for seasonal and annual flow projections in the longer term (2060s). Although the uncertainty due to RCPs is large for the peak and annual sediment load projections, model parameterization uncertainty can play a significant role in uncertainty of the sediment projections for the 2030s period. Our results also suggest that there is more uncertainty in sediment loads than flow projections.

In general, our study highlights that it is essential to investigate the major contributing sources of uncertainty in large basins over time and at different scales, as this can have important consequences for decision making on flow and sediment management as part of adaptation to climate change implications. Careful investigation of sources of uncertainty is an important step for decision making as it helps to improve characterization of uncertainties and avoid an overconfident portrayal of climate change impacts (Mendoza et al., 2014). Decision making under climate change should be based on assessments of risk of potential outcomes rather than traditional norm-based probability assessments (Juston et al., 2013). Overall, there are two major practical uses of uncertainty assessments: (1) through uncertainty analysis we produce more reliable and robust predictions (Addor et al., 2014) and (2) we will be able to better communicate 
risk, which can be essential in gaining and retaining the trust of the public (Juston et al., 2013).. This is more important for sediment projections because impact of climate change on sediment yield is expected to be greater than on flow. Further, since model parameterization uncertainty can be significant for flow and sediment projections, there is a need to incorporate parameter uncertainty in climate change studies and efforts to reduce the parameter uncertainty as much as possible should be considered through a careful calibration and validation. Land use/land cover could also be an important influence in model projections, and future work will evaluate the uncertainty associated with this factor.

\section{Acknowledgements}

Special thanks to the University of Canterbury for providing a UC Doctoral Scholarship to the first author. Funds for travel and data collection were provided by the John D. and Catherine T. MacArthur Foundation through a project entitled " Critical Basin at Risk: Assessing and managing ecosystem pressures from development and climate change in the $3 \mathrm{~S}$ basin". This manuscript was completed while M. E. Arias was a Giorgio Ruffolo Fellow in the Sustainability Science Program at Harvard University and the support from Italy's Ministry for Environment, Land and Sea is gratefully acknowledged. We also gratefully acknowledge the Mekong River Commission for providing all necessary data required for the study. Special thanks to Dr. Dat Nguyen Dinh and Dr. Ornanorg Vonnarart of Information and Knowledge Management Programme, MRC for putting together all the database for the 3S SWAT model.

\section{References}

Abbaspour, K.C., 2008. SWAT-CUP2: SWAT calibration and uncertainty programs - A user manual. , Department of Systems Analysis, Integrated Assessment and Modelling (SIAM), Eawag, Swiss Federal Institute of Aquatic Science and Technology, Duebendorf, Switzerland.

Abbaspour, K.C., Johnson, C.A., van Genuchten, M.T., 2004. Estimating uncertain flow and transport parameters using a sequential uncertainty fitting procedure. Vadose Zone Journal, 3(4): 13401352.

Abbaspour, K.C. et al., 2007. Modelling hydrology and water quality in the pre-alpine/alpine Thur watershed using SWAT. Journal of Hydrology, 333(2-4): 413-430. DOI:http://dx.doi.org/10.1016/j.jhydrol.2006.09.014

Adamson, P.T., Rutherfurd, I.D., Peel, M.C., Conlan, I.A., 2009. The hydrology of the Mekong River. The Mekong, Academic Press, San Diego, 53-76 pp.

Addor, N. et al., 2014. Robust changes and sources of uncertainty in the projected hydrological regimes of Swiss catchments. Water Resources Research, 50(10): 7541-7562. DOI:10.1002/2014WR015549 
680

681

682

683

684

685

686

687

688

689

690

691

692

Arias, M.E., Piman, T., Lauri, H., Cochrane, T.A., Kummu, M., 2014. Dams on Mekong tributaries as significant contributors of hydrological alterations to the Tonle Sap Floodplain in Cambodia. Hydrology and Earth System Sciences, 18(12): 5303-5315. DOI:10.5194/hess-18-5303-2014

Arnold, J.G. et al., 2012. SWAT: Model Use, Calibration, and Validation. Transactions of the Asabe, 55(4): 1491-1508.

Arnold, J.G., Srinivasan, R., Muttiah, R.S., Williams, J.R., 1998. Large area hydrologic modeling and assessment. Part I: Model development. Journal of American Water Resources Association, 34(1): 73-89.

Bennett, K.E., Werner, A.T., Schnorbus, M., 2012. Uncertainties in Hydrologic and Climate Change Impact Analyses in Headwater Basins of British Columbia. Journal of Climate, 25(17): 57115730. DOI:10.1175/jcli-d-11-00417.1

Berc, J., Lawford, R., Bruce, J., Mearns, L., Easterling, D., 2003. Conservation Implications of Climate Change: Soil Erosion and Runoff from Croplands: A Report from the Soil and Water Conservation Society. Ankeny (IA): Soil and Water Conservation Society.

Bogaart, P.W., Van Balen, R.T., Kasse, C., Vandenberghe, J., 2003. Process-based modelling of fluvial system response to rapid climate change - I: model formulation and generic applications. Quaternary Science Reviews, 22(20): 2077-2095. DOI:10.1016/s0277-3791(03)00143-4

Chen, J., Brissette, F.P., Poulin, A., Leconte, R., 2011. Overall uncertainty study of the hydrological impacts of climate change for a Canadian watershed. Water Resources Research, 47. DOI:10.1029/2011wr010602

Chen, X., Yang, T., Wang, X., Xu, C.Y., Yu, Z., 2013. Uncertainty Intercomparison of Different Hydrological Models in Simulating Extreme Flows. Water Resour Manage, 27(5): 1393-1409.

Clark, M.P., Kavetski, D., Fenicia, F., 2011. Pursuing the method of multiple working hypotheses for hydrological modeling. Water Resources Research, 47(9).

Cochrane, T.A., Arias, M.E., Piman, T., 2014. Historical impact of water infrastructure on water levels of the Mekong River and the Tonle Sap system. Hydrology and Earth System Sciences, 18(11): 4529-4541. DOI:10.5194/hess-18-4529-2014

Dai, S., Yang, S., Li, M., 2009. The sharp decrease in suspended sediment supply from China's rivers to the sea: anthropogenic and natural causes. Hydrological Sciences Journal, 54(1): 135-146.

Gädeke, A., Hölzel, H., Koch, H., Pohle, I., Grünewald, U., 2014. Analysis of uncertainties in the hydrological response of a model-based climate change impact assessment in a subcatchment of the Spree River, Germany. Hydrological Processes, 28(12): 3978-3998. DOI:10.1002/hyp.9933

Gan, T.Y., Dlamini, E.M., Biftu, G.F., 1997. Effects of model complexity and structure, data quality, and objective functions on hydrologic modeling. Journal of Hydrology, 192(1-4): 81-103. DOI:10.1016/S0022-1694(96)03114-9

Gassman, P.W., Sadeghi, A.M., Srinivasan, R., 2014. Applications of the SWAT Model Special Section: Overview and Insights. J. Environ. Qual., 43(1): 1-8. DOI:10.2134/jeq2013.11.0466

Girvetz, E.H. et al., 2009. Applied Climate-Change Analysis: The Climate Wizard Tool. Plos One, 4(12). DOI:10.1371/journal.pone.0008320

Gong, Y.W., Shen, Z.Y., Liu, R.M., Hong, Q., Wu, X., 2012. A comparison of single- and multi-gauge based calibrations for hydrological modeling of the Upper Daning River Watershed in China's Three Gorges Reservoir Region. Hydrology Research, 43(6): 822-832. DOI:10.2166/nh.2012.021

Gray, J.R., Glysson, G.D., Turcios, L.M., Schwarz, G.E., 2000. Comparability of suspended-sediment concentration and total suspended solids data., US Department of the Interior, US Geological Survey. .

Gupta, H.V., Kling, H., Yilmaz, K.K., Martinez, G.F., 2009. Decomposition of the mean squared error and NSE performance criteria: Implications for improving hydrological modelling. Journal of Hydrology, 377(1-2): 80-91. DOI:10.1016/j.jhydrol.2009.08.003

Guy, H.P., Norman, V.W., 1970. Field methods for measurement of fluvial sediment, US Govt. Print. Off. 
Hanratty, M.P., Stefan, H.G., 1998. Simulating climate change effects in a Minnesota agricultural watershed. J. Environ. Qual., 27(6): 1524-1532.

Hardy, R.L., 1971. Multiquadric equations of topology and other irregular surface. Journal of Geophysical Research, 76: 1905 - 1915.

Harrison, C., 2000. What factors control mechanical erosion rates? International Journal of Earth Sciences, 88(4): 752-763.

Hawkins, E., Sutton, R., 2011. The potential to narrow uncertainty in projections of regional precipitation change. Clim. Dyn., 37(1-2): 407-418. DOI:10.1007/s00382-010-0810-6

Jackson, W.L., Gebhardt, K., Van Haveren, B.P., 1986. Use of the modified universal soil loss equation for average annual sediment yield estimates on small rangeland drainage basins. Drainage basin sediment delivery. Proc. symposium, Albuquerque, 1986: 413-422.

Jiang, T. et al., 2007. Comparison of hydrological impacts of climate change simulated by six hydrological models in the Dongjiang Basin, South China. Journal of Hydrology, 336(3-4): 316333. DOI:10.1016/j.jhydrol.2007.01.010

Johnson, C.W., Gordon, N.D., Hanson, C.L., 1986. North-west rangeland sediment yield analysis by the MUSLE. Transactions of the American Society of Agricultural and Biological Engineers, 26: 1889-1895.

Juston, J.M. et al., 2013. Smiling in the rain: Seven reasons to be positive about uncertainty in hydrological modelling. Hydrological Processes, 27(7): 1117-1122. DOI:10.1002/hyp.9625

Kay, A.L., Davies, H.N., Bell, V.A., Jones, R.G., 2009. Comparison of uncertainty sources for climate change impacts: Flood frequency in England. Climatic Change, 92(1-2): 41-63.

Kenny, G.J., Warrick, R.A., Mitchell, N.D., Mullan, A.B., Salinger, M.J., 1995. CLIMPACTS: an integrated model for assessment of the effects of climate change on the New Zealand environment. Journal of Biogeography, 22(4-5): 883-895.

Khan, M.S., Coulibaly, P., Dibike, Y., 2006. Uncertainty analysis of statistical downscaling methods. Journal of Hydrology, 319(1): 357-382.

Kingston, D.G., Thompson, J.R., Kite, G., 2011. Uncertainty in climate change projections of discharge for the Mekong River Basin. Hydrology and Earth System Sciences, 15: 1459-1471. DOI:10.5194/hess-15-1459-2011

Koehnken, L., 2012. IKMP Discharge and Sediment Monitoring Program Review, Recommendations and Data Analysis (No. Part 2: Data analysis of preliminary results). , Information and Knowledge Management Programme, Mekong River Comission, Vientaine, Lao PDR.

Koehnken, L., 2014. Discharge sediment monitoring project (DSMP) 2009-2013 summary and analysis of results, Mekong River Commission/Gesellschaft für Internationale Zusammenarbeit, Phnom Penh, Cambodia.

Kondolf, G.M., Rubin, Z.K., Minear, J.T., 2014. Dams on the Mekong: Cumulative sediment starvation. Water Resources Research, 50(6): 5158-5169. DOI:10.1002/2013WR014651

Krause, P., Boyle, D.P., Bäse, F., 2005. Comparison of different efficiency criteria for hydrological model assessment. Advances in Geosciences, 5: 89-97.

Kummu, M., Lu, X.X., Wang, J.J., Varis, O., 2010. Basin-wide sediment trapping efficiency of emerging reservoirs along the Mekong. Geomorphology, 119(3-4): 181-197. DOI:10.1016/j.geomorph.2010.03.018

Li, Y., Chen, B.M., Wang, Z.G., Peng, S.L., 2011. Effects of temperature change on water discharge, and sediment and nutrient loading in the lower Pearl River basin based on SWAT modelling. Hydrological Sciences Journal-Journal Des Sciences Hydrologiques, 56(1): 68-83. DOI:10.1080/02626667.2010.538396

Lu, X., Kummu, M., Oeurng, C., 2014. Reappraisal of sediment dynamics in the Lower Mekong River, Cambodia. Earth Surface Processes and Landforms, 39(14): 1855-1865. DOI:10.1002/esp.3573

Ma, X., Lu, X.X., van Noordwijk, M., Li, J.T., Xu, J.C., 2014. Attribution of climate change, vegetation restoration, and engineering measures to the reduction of suspended sediment in the Kejie 
catchment, southwest China. Hydrol. Earth Syst. Sci., 18(5): 1979-1994. DOI:10.5194/hess-181979-2014

Masih, I., Maskey, S., Uhlenbrook, S., Smakhtin, V., 2011. Assessing the Impact of Areal Precipitation Input on Streamflow Simulations Using the SWAT Model1. Journal of the American Water Resources Association, 47(1): 179-195. DOI:10.1111/j.1752-1688.2010.00502.x

Maurer, E.P., 2007. Uncertainty in hydrologic impacts of climate change in the Sierra Nevada, California, under two emissions scenarios. Climatic Change, 82: 309-325.

Mendoza, P.A. et al., 2015. How do the selection and configuration of hydrologic models affect the portrayal of climate change impacts? Hydrological Processes: n/a-n/a. DOI:10.1002/hyp.10684

Mendoza, P.A. et al., 2014. Effects of Hydrologic Model Choice and Calibration on the Portrayal of Climate Change Impacts. Journal of Hydrometeorology, 16(2): 762-780. DOI:10.1175/JHM-D14-0104.1

Moriasi, D.N. et al., 2007. Model evaluation guidelines for systematic quantification of accuracy in watershed simulations. Transactions of the ASABE, 50(3): 885-900.

MRC, 2010. Stage 2 development of MRC Toolbox: Final report (WP016), Information and Knowledge Management Programme, Mekong River Commission (MRC), Phnom Penh, Cambodia

MRC, 2011. Application of MRC modelling tools in the 3S basin, Mekong River Commission (MRC), Phnom Penh, Cambodia

MRC, 2015. 1st Draft Report on Defining basin-wide climate change scenarios for the Lower Mekong Basin (LMB), Mekong River Commission (MRC), Phnom Penh, Cambodia

Muleta, M.K., Nicklow, J.W., 2005. Sensitivity and uncertainty analysis coupled with automatic calibration for a distributed watershed model. Journal of Hydrology, 306(1-4): 127-145. DOI:http://dx.doi.org/10.1016/j.jhydrol.2004.09.005

Najafi, M.R., Moradkhani, H., Jung, I.W., 2011. Assessing the uncertainties of hydrologic model selection in climate change impact studies. Hydrological Processes, 25(18): 2814-2826.

Nash, J.E., Sutcliffe, J.V., 1970. River flow forecasting through conceptual models part I - A discussion of principles. Journal of Hydrology, 10(3): 282-290. DOI:http://dx.doi.org/10.1016/00221694(70)90255-6

Ndomba, P.M., Mtalo, F.W., Killingtveit, A., 2008a. A guided SWAT model application on sediment yield modeling in Pangani river basin: Lessons learnt. Journal of Urban and Environmental Engineering, 2(2): 53-62. DOI:10.4090/juee.2008.v2n2.053062

Ndomba, P.M., Mtalo, F.W., Killingtveit, A., 2008b. SWAT model application in a data scarce tropical complex catchment in Tanzania. Physics and Chemistry of the Earth, 33(8-13): 626-632. DOI:10.1016/j.pce.2008.06.013

Neitsch, S.L., Arnold, J.G., Kiniry, J.R., Williams, J.R., 2011. Soil and Water Assessment Tool theoretical documentation, version 2009, Texas Water Resources Institute, College Station, Texas, USA.

Partheniades, E., 1977. Unified view of wash load and bed material load. Journal of the Hydraulics Division, 103(9): 1037-1057.

Piman, T., Cochrane, T.A., Arias, M.E., Green, A., Dat, N.D., 2013. Assessment of Flow Changes from Hydropower Development and Operations in Sekong, Sesan, and Srepok Rivers of the Mekong Basin. Journal of Water Resources Planning and Management, 139(6): 723-732. DOI:10.1061/(asce)wr.1943-5452.0000286

Refsgaard, J.C., Storm, B., 1996. Construction, Calibration And Validation of Hydrological Models. In: Abbott, M., Refsgaard, J. (Eds.), Distributed Hydrological Modelling. Water Science and Technology Library. Springer Netherlands, pp. 41-54. DOI:10.1007/978-94-009-0257-2_3

Rostamian, R. et al., 2008. Application of a SWAT model for estimating runoff and sediment in two mountainous basins in central Iran. Hydrological Sciences Journal, 53(5): 977-988. DOI:10.1623/hysj.53.5.977 
Runkel, R.L., Crawfored, C.G., Cohn, T.A., 2004. Load Estimator (LOADEST): A FORTAN program for estimating constituent loads in streams and rivers. U.S. Geological Survey, Reston, Virginia (USA). .

Servat, E., Dezetter, A., 1991. Selection of calibration objective functions in the context of rainfall-runoff modelling in a Sudanese savannah area. Hydrological Sciences Journal/Journal des Sciences Hydrologiques, 36(4): 307-330.

Setegn, S.G., Srinivasan, R., Melesse, A.M., Dargahi, B., 2010. SWAT model application and prediction uncertainty analysis in the Lake Tana Basin, Ethiopia. Hydrological Processes, 24(3): 357-367. DOI:10.1002/hyp.7457

Shaw, E.H., Lynn, P.P., 1972. Areal rainfall using two surface fitting techniques, Bulletin of the International Association and Hydrological Science, XVII,. 4-2.

Shrestha, B. et al., 2013. Impact of climate change on sediment yield in the Mekong River basin: a case study of the Nam Ou basin, Lao PDR. Hydrology and Earth System Sciences, 17(1): 1-20. DOI: 10.5194/hess-17-1-2013

Sperber, K. et al., 2013. The Asian summer monsoon: an intercomparison of CMIP5 vs. CMIP3 simulations of the late 20th century. Clim. Dyn., 41(9-10): 2711-2744. DOI:10.1007/s00382-0121607-6

Srinivasan, R., Ramanarayanan, T.S., Arnold, J.G., Bednarz, S.T., 1998. Large area hydrologic modeling and assessment. Part II: Model application. Journal of American Water Resources Association, 34(1): 91-101.

Surfleet, C.G., Tullos, D., 2013. Uncertainty in hydrologic modelling for estimating hydrologic response due to climate change (Santiam River, Oregon). Hydrological Processes, 27(25): 3560-3576. DOI:10.1002/hyp. 9485

Syvitski, J.P.M., Peckham, S.D., Hilberman, R., Mulder, T., 2003. Predicting the terrestrial flux of sediment to the global ocean: a planetary perspective. Sedimentary Geology, 162(1-2): 5-24. DOI:10.1016/s0037-0738(03)00232-x

Thompson, J.R., Green, A.J., Kingston, D.G., Gosling, S.N., 2013. Assessment of uncertainty in river flow projections for the Mekong River using multiple GCMs and hydrological models. Journal of Hydrology, 486: 1-30. DOI:10.1016/j.jhydrol.2013.01.029

Vetter, T. et al., 2015. Multi-model climate impact assessment and intercomparison for three large-scale river basins on three continents. Earth System Dynamics, 6(1): 17-43. DOI:10.5194/esd-6-172015

Walling, D., 2005. Evaluation and analysis of sediment data from the Lower Mekong River. Report prepared for the Mekong River Commission.

Walling, D.E., 2008. The changing sediment load of the Mekong River. Ambio, 37(3): 150-157. DOI:10.1579/0044-7447(2008)37[150:TCSLOT]2.0.CO;2

Wilby, R.L., Harris, I., 2006. A framework for assessing uncertainties in climate change impacts: Lowflow scenarios for the River Thames, UK. Water Resources Research, 42(2). DOI:10.1029/2005wr004065

Wild, T.B., Loucks, D.P., 2014. Managing flow, sediment, and hydropower regimes in the Sre Pok, Se San, and Se Kong Rivers of the Mekong basin. Water Resources Research, 50(6): 5141-5157. DOI:10.1002/2014WR015457

Yang, J., Reichert, P., Abbaspour, K.C., Xia, J., Yang, H., 2008. Comparing uncertainty analysis techniques for a SWAT application to the Chaohe Basin in China. Journal of Hydrology, 358(12): 1-23. DOI:10.1016/j.jhydrol.2008.05.012

Yip, S., Ferro, C.A.T., Stephenson, D.B., Hawkins, E., 2011. A Simple, Coherent Framework for Partitioning Uncertainty in Climate Predictions. Journal of Climate, 24(17): 4634-4643. DOI:10.1175/2011JCLI4085.1

Zhang, C., Chu, J.G., Fu, G.T., 2013. Sobol"s sensitivity analysis for a distributed hydrological model of Yichun River Basin, China. Journal of Hydrology, 480: 58-68. DOI:10.1016/j.jhydrol.2012.12.005 
Zhang, X., Nearing, M., 2005. Impact of climate change on soil erosion, runoff, and wheat productivity in central Oklahoma. Catena, 61(2): 185-195.

Zhang, X., Xu, Y.P., Fu, G., 2014. Uncertainties in SWAT extreme flow simulation under climate $\begin{array}{llll}\text { change. Journal of 205-222. } & \text { Hydrology, }\end{array}$ DOI:http://dx.doi.org/10.1016/j.jhydrol.2014.04.064

Zhu, Y.-M., Lu, X.X., Zhou, Y., 2008. Sediment flux sensitivity to climate change: A case study in the Longchuanjiang catchment of the upper Yangtze River, China. Global and Planetary Change, 60(3-4): 429-442. DOI:10.1016/j.gloplacha.2007.05.001

Ziv, G., Baran, E., Nam, S., Rodriguez-Iturbe, I., Levin, S.A., 2012. Trading-off fish biodiversity, food security, and hydropower in the Mekong River Basin. Proceedings of the National Academy of Sciences of the United States of America, 109(15): 5609-5614. DOI:10.1073/pnas.1201423109 